\title{
Evaluasi kualitas skenario Problem-Based Learning di Fakultas Kedokteran Universitas Sam Ratulangi
}

\author{
Yanti M. Mewo \\ Firginia P. Manoppo \\ Herlina I.S. Wungouw
}

\begin{abstract}
Unit Pendidikan Kedokteran Fakultas Kedokteran Universitas Sam Ratulangi Manado Email: yanti.mewo@gmail.com
\end{abstract}

\begin{abstract}
Implementation of Problem Based Learning (PBL) in a tutorial discussion is not separable from the role of tutorial problems which are used to trigger the learning process. Excellent problems are needed for the success of PBL. The evaluation of PBL problems can provide an overview of strengths and weakness as well as inputs for improving the quality of problems. This study was aimed to evaluate the quality of PBL problems in Faculty of Medicine, Sam Ratulangi University Manado. We used modified questionnaire of Munshi et al. Respondents were asked to answer Likert scale questionnaires which consisted of 18 items added with one item for the overall rating of the PBL problem. The results showed that of a total of 6 problems evaluated by students and tutors, both tutors and students agreed that the weakest aspect was that the problem did not phrase to student perception of their own environment and culture (item 11). The strongest aspect identified by tutors was students were familiar with part of the knowledge necessary for discussing the problem (item 18). The strongest aspect according to students was related to the linkage of the problems with the future profession (item 13). Conclusion: The PBL problems in Faculty of Medicine, Sam Ratulangi University still needed to be improved. Some aspects had been identified as strengths and weaknesses; those could be used to improve the quality of problems.
\end{abstract}

Keywords: Problem Based Learning, PBL problems, PBL tutorial

\begin{abstract}
Abstrak: Penerapan PBL dalam diskusi tutorial tidak lepas dari peran skenario berisikan masalah pasien yang digunakan sebagai pemicu pembelajaran mahasiswa. Skenario PBL yang memiliki kualitas baik sangat penting bagi keberhasilan pembelajaran dengan metode PBL. Evaluasi skenario PBL dapat memberikan gambaran kekuatan dan kelemahan yang dapat dijadikan sebagai masukan untuk meningkatkan kualitas skenario PBL. Penelitian ini bertujuan untuk mengevaluasi kualitas skenario PBL di Fakultas Kedokteran Universitas Sam Ratulangi (FK Unsrat) Manado. Instrumen yang digunakan ialah kuesioner dari Munshi et al. Responden diminta memberikan penilaian 18 pernyataan dan satu pertanyaan penilaian secara umum berdasarkan skala Likert. Enam skenario PBL dinilai oleh tutor dan mahasiswa. Hasil penelitian mendapatkan bahwa baik tutor maupun mahasiswa setuju bahwa yang menjadi kelemahan berkaitan dengan skenario PBL yang disusun tidak sesuai dengan wawasan mahasiswa tentang lingkungan dan kebudayaan (item 11). Menurut tutor, yang menjadi kelebihan yaitu mahasiswa telah mengenal sebagian pengetahuan yang diperlukan untuk mendiskusikan skenario (item 18). Evaluasi oleh mahasiswa didapatkan bahwa skenario menunjukkan hubungan jelas dengan profesi di masa depan merupakan kelebihan dari skenario PBL yang digunakan di FK Unsrat (item 13). Simpulan: Skenario PBL di FK Unsrat masih memerlukan perbaikan. Didapatkan beberapa aspek yang diidentifikasi sebagai kekuatan dan kelemahan yang dapat dipakai untuk meningkatakan kualitas skenario PBL di FK Unsrat.
\end{abstract}

Kata kunci: Problem Based Learning, scenario PBL, tutorial PBL 
Problem-based learning (PBL) yang diperkenalkan sejak tahun 1969 di Universitas Mc Master Kanada telah memberikan dampak perubahan pada banyak aspek dalam kurikulum pendidikan kedokteran. ${ }^{1}$ Di Indonesia, PBL diterapkan sebagai salah satu strategi atau pendekatan dalam kurikulum pendidikan dokter yang dikenal dengan Kurikulum Berbasis Kompetensi (KBK). Penerapan PBL di Indonesia mengacu pada pendekatan SPICES yang dikemukakan oleh Harden dan Dent, yang merupakan singkatan dari Studentcentered, Problem-based, Integrated, Community based, Elective/Early clinical exposure, Systematic. ${ }^{2}$

Pembelajaran merupakan proses aktif dalam membangun pengetahuan, yang tidak hanya bersifat mengingat secara pasif. Suatu metode instruksional dalam pembelajaran harus dapat merangsang mahasiswa dengan mengaktivasi pengetahuan awal mereka yang relevan dengan pengetahuan yang ingin dicapai. Metode instruksional juga harus memberikan keadaan yang serupa dengan keadaan yang akan mahasiswa hadapi pada praktek nyatanya di kemudian hari. Lingkungan pembelajaran harus memberikan kesempatan bagi mahasiswa untuk mengelaborasi pengetahuan mereka. Problem-based learning (PBL) merupakan suatu metode instruksional yang dikatakan dapat menyediakan kondisi tersebut. ${ }^{3,4}$

Melalui penerapan PBL, diharapkan lulusan dokter Indonesia dapat kompeten dalam pengetahuan, keterampilan dan sikap yang selaras dengan tujuh area kompetensi yang ditetapkan oleh Konsil Kedokteran Indonesia. ${ }^{2}$ Dalam penerapan PBL, sesi diskusi tutorial berperan besar dalam mencapai beberapa kompetensi tersebut.

Penerapan PBL dalam diskusi tutorial tidak terlepas dari peran skenario yang berisikan masalah pasien atau fenomena fisiologi, biologi, psikologi, atau sosial yang digunakan sebagai pemicu pembelajaran mahasiswa. ${ }^{3}$ Aktivitas pembelajaran dimulai dengan sebuah masalah, yang merupakan suatu deskripsi dari serangkaian gejala, fenomena atau situasi yang saling berkaitan yang membutuhkan pembahasan dari baik segi proses yang mendasari serta prinsip atau mekanisme terjadinya masalah tersebut. ${ }^{3,5}$

Hasil penelitian dari Schmidt dan Gijselaers yang dikutip oleh Munshi menunjukkan bahwa banyaknya pengetahuan awal (prior knowledge), kualitas masalah, dan performa tutor merupakan faktor yang penting dan berpengaruh dalam proses pembelajaran PBL. Namun, faktor yang paling dominan memberikan pengaruh dalam proses PBL ialah kualitas masalah (dalam skenario) yang diajukan kepada mahasiswa. ${ }^{3}$

Dolmans et al. ${ }^{6}$ menulis beberapa prinsip skenario PBL yang efektif. Skenario harus sesuai dengan level pengetahuan awal mahasiswa; jelas hubungannya dengan profesi mahasiswa di masa mendatang; mengandung petunjuk yang dapat mendorong elaborasi; mendorong integrasi konsep pengetahuan dasar dan klinik; menstimulasi self-directed learning; menarik minat mahasiswa; dan sesuai dengan tujuan pembelajaran.

Masalah dalam skenario yang memiliki kualitas yang baik sangat penting bagi keberhasilan proses pembelajaran dengan metode PBL. Di FK Unsrat, pada setiap modul terdapat sesi diskusi tutorial yang membahas dan mendiskusikan masalah dalam bentuk skenario kasus. Sesi tutorial merupakan salah satu metode pembelajaran penting di FK Unsrat yang mendukung mahasiswa dalam membangun pengetahuannya masing-masing.

Penelitian oleh Munshi et al. $^{3}$ di Fakultas Kedokteran KFMC di Saudi Arabia berhasil mengembangkan suatu instrumen dengan beberapa parameter sebagai dasar untuk mengevaluasi kualitas skenario PBL. Penelitian ini bertujuan untuk mendapatkan gambaran mengenai kualitas skenario yang digunakan dalam PBL di Fakultas Kedokteran Unsrat berdasarkan evaluasi oleh tutor dan mahasiswa.

\section{METODE PENELITIAN}

Penelitian ini dilaksanakan di FK Unsrat pada Program Studi Pendidikan 
Dokter semester genap tahun akademik 2016. Kurikulum pada program studi ini terdiri dari 7 semester untuk mencapai tahap sarjana kedokteran. Setiap semester terdiri dari 8-10 modul dengan lama pembelajaran tiap modul berkisar 2-3 minggu. Rata-rata dalam setiap modul terdapat dua skenario yang menjadi pemicu untuk pembelajaran dalam diskusi tutorial. Tiap skenario dibahas dalam dua sesi diskusi dengan menggunakan metode tujuh langkah dari Maastricht.

Skenario yang dievaluasi sebanyak enam skenario. Diambil masing-masing dua skenario dari modul Metabolisme semester 2; modul Hati, Empedu, dan Pankreas semester 4; dan dua dari modul Gangguan Kulit semester 6 .

Instrumen yang digunakan ialah modifikasi dari kuesioner yang dikembangkan oleh Munshi et al. Kuesioner ini terdiri dari 18 pernyataan yang merupakan penjabaran dari enam faktor yang menentukan kualitas skenario. Skenario PBL yang baik: dapat memicu mahasiswa untuk berpikir, menganalisis, dan bernalar (pernyataan 1-3); mendorong self-directed learning (pernyataan 4-6); mendorong mahasiswa untuk belajar materi-materi pelajaran yang terkait (pernyataan 7-9); meningkatkan ketertarikan terhadap materi pelajaran (pernyataan 10-12); relevan dengan profesi di masa depan (pernyataan 13-15); dan sesuai dengan prior knowledge (pernyataan 1618). Terdapat juga satu pernyataan (nomor 19) yang merupakan penilaan secara keseluruhan terhadap kualitas skenario.

Kuesioner dibagikan kepada seluruh mahasiswa $(\mathrm{N}=689)$ dan tutor $(\mathrm{N}=53)$ yang hadir setelah diskusi sesi kedua. Mahasiswa dan tutor diminta menilai setiap pernyataan kuesioner dengan menggunakan skala Likert $(1=$ sangat tidak setuju; $2=$ tidak setuju; $3=$ netral; $4=$ setuju; $5=$ sangat setuju). Standar untuk menginter-pretasikan penilaian setiap pernyataan yaitu: $\leq 3$ ialah tidak cukup; nilai rata-rata $>3-3,5$ dianggap perlu perbaikan; >3,5-4 dinilai cukup; dan $>4$ dinilai baik. Untuk penilaian keseluruhan (nomor 19) yaitu dalam rentang 1 sampai 5. Nilai 1 dianggap mempunyai kualitas yang kurang dan nilai 5 menggambarkan kualitas skenario yang sangat baik.

\section{HASIL PENELITIAN DAN BAHASAN}

Penilaian skenario oleh tutor untuk setiap pernyataan dari seluruh skenario berada pada rentang 3,75 $(\mathrm{SD}=0,73, \mathrm{~N}=53)$ sampai 4,16 $(\mathrm{SD}=1,5, \mathrm{~N}=53)$. Penilaian oleh mahasiswa mulai dari 3,59 ( $\mathrm{SD}=0,81$, $\mathrm{N}=689)$ sampai 4,1 ( $\mathrm{SD}=0,69, \mathrm{~N}=689)$. Secara keseluruhan nilai rerata dari setiap pernyataan untuk keenam skenario dapat dilihat pada Gambar 1. Hasil penilaian oleh tutor dan mahasiswa didapatkan tidak ada pernyataan yang mempunyai nilai rerata $<3,5$. Sebagian berada dikategori cukup (nilai rerata $>3,5$ ) dan sebagian lagi baik (nilai rerata $>4$ ).

Pernyataan yang mendapatkan nilai terendah dari tutor tetapi masih dikategori cukup baik ialah pernyataan nomor 11 . Mahasiswa mempunyai pendapat yang sama dengan tutor mengenai hal ini. Pernyataan ini berkaitan dengan kesesuaian skenario dengan wawasan mahasiswa tentang lingkungan dan kebudayaan mereka. Beberapa hal yang harus diperhatikan dalam menyusun skenario PBL antara lain: disajikan dalam konteks masalah yang relevan dan cocok dengan minat dan persepsi mahasiswa sehingga skenario yang disusun mendorong mahasiswa untuk menghubungkan materi ilmiah yang dipelajari dengan masalah di dunia nyata dan meningkatkan motivasi mahasiswa untuk belajar. $^{5}$

Pernyataan nomor 18 mempunyai nilai rerata tertinggi dari penilaian tutor. Pernyataan ini menggambarkan bahwa mahasiswa telah mengenal sebagian pengetahuan yang diperlukan untuk mendiskusikan skenario. Salah satu kriteria dari skenario PBL yang baik yaitu harus berada pada tingkat kompleksitas yang sesuai dan dapat merujuk pada pengetahuan sebelumnya yang telah dimiliki mahasiswa. Skenario harus mengarahkan mahasiswa untuk melakukan analisis dan sintesis pengetahuan awal dengan pengetahuan baru.

Pernyataan dengan nilai rerata tertinggi dari penilaian mahasiswa yaitu pernyataan 
nomor 13 yaitu: skenario menunjukkan hubungan yang jelas dengan profesi di masa depan. Hal ini cukup jelas karena keenam skenario mengadopsi kasus klinik yang sering ditemukan yang akan ditangani oleh mahasiswa ketika mereka lulus.

Untuk kualitas secara umum dari masing-masing skenario dapat dinilai dari pernyataan nomor 19 . Tutor memberikan nilai dalam rentang 3,4 $(\mathrm{SD}=0,50, \mathrm{~N}=6)$ sampai 4,1 $(\mathrm{SD}=0,9, \mathrm{~N}=12)$. Penilaian oleh mahasiswa berada pada rentang 3,12 $(\mathrm{SD}=1,00, \mathrm{~N}=74)$ sampai $3,82(\mathrm{SD}=0,70, \mathrm{~N}$ $=195$ ). Hasil nilai rata-rata penilaian ini dapat dilihat pada Gambar 2.

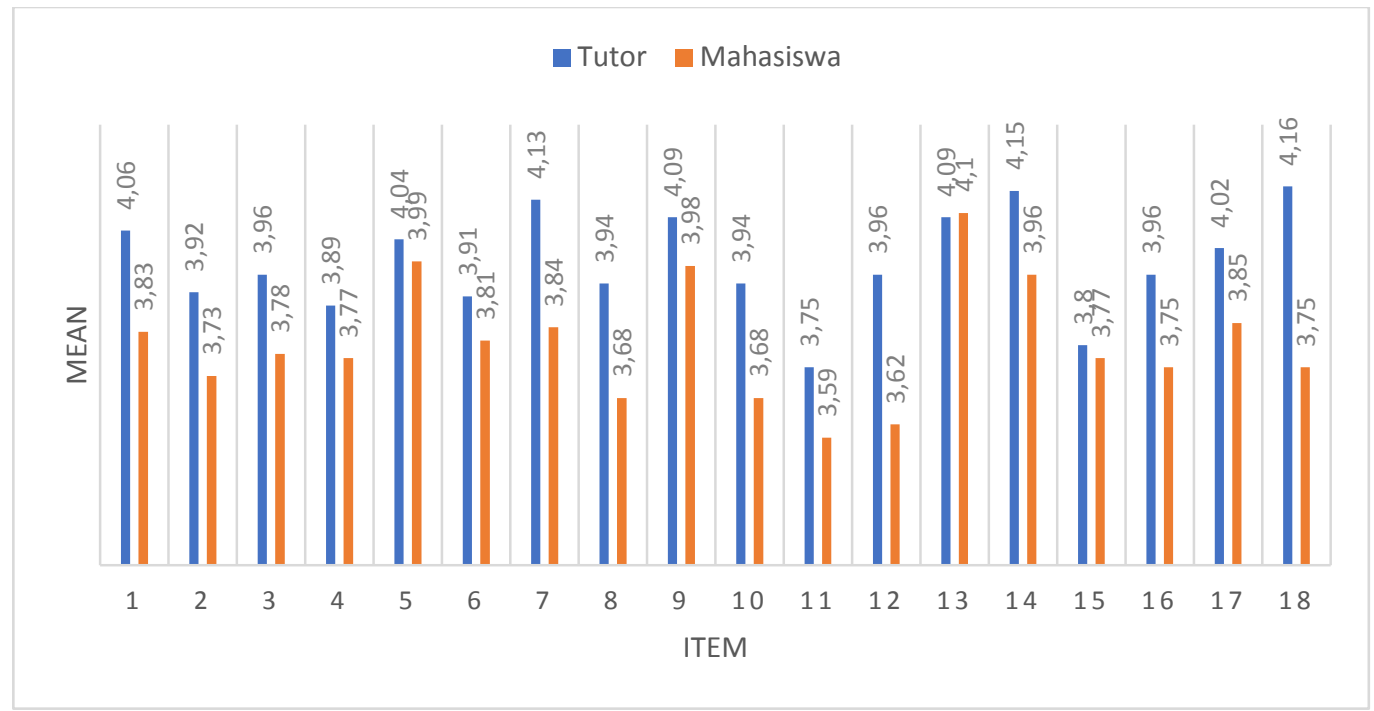

Gambar 1. Grafik nilai rerata item 1 s.d. 18 untuk keseluruhan skenario dari skala 1 (sangat tidak setuju) sampai 5 (sangat setuju)

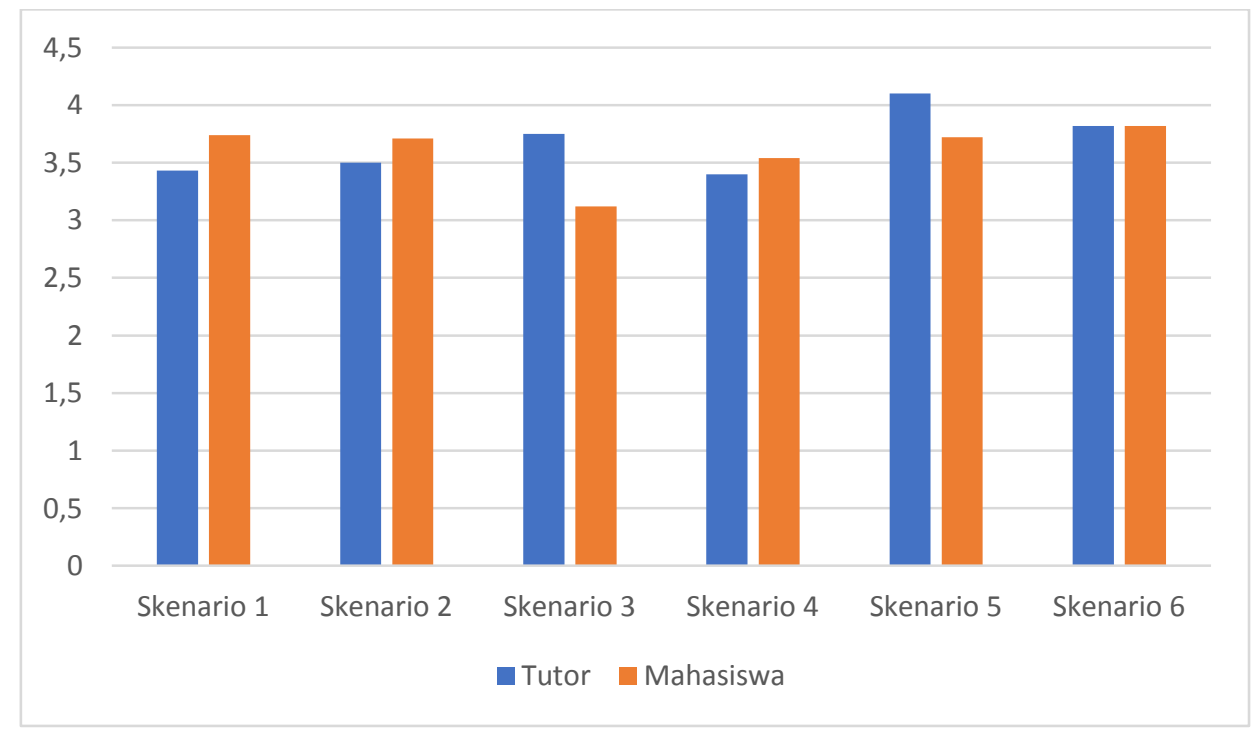

Gambar 2. Grafik nilai rerata masing-masing skenario berdasarkan pernyataan nomor 19 yang menilai kualitas skenario secara umum dari skala 1 (tidak cukup) sampai 5 (sangat baik)

Dari hasil penilaian dengan mengggunakan pernyataan nomor 19 yang digam- barkan pada Gambar 2 dapat dilihat bahwa semua skenario berada dalam rentang nilai 
'cukup' sampai 'baik', yaitu skala 3-4.

Skenario 3 merupakan skenario yang mendapatkan nilai rerata paling rendah yaitu 3,12 ( $\mathrm{SD}=1, \mathrm{~N}=74)$. Pada Tabel 1 di bawah ini dapat dilihat nilai rata-rata setiap pernyataan dari 1 sampai 18 . Menurut tutor pernyataan yang mempunyai nilai terendah sama seperti penilaian skena-rio secara keseluruhan yaitu pernyataan nomor 11 (nilai rerata $=3,5$ ). Dari penilaian mahasiswa didapatkan beberapa pernyataan mempunyai nilai rerata $3-3,5$ yang berarti memerlukan perbaikan, yaitu pernyataan nomor $1,2,6,10,11,12,16,18$. Terdapat 1 pernyataan yang mendapat nilai $<3$, yaitu pernyataan nomor 3 mengenai skenario mengandung petunjuk sebagai pemicu diskusi.

Skenario 3 (Gambar 3) mendapat nilai yang kurang pada pernyataan nomor 3 . Mahasiswa menilai skenario ini tidak memiliki pemicu yang cukup untuk jalannya diskusi sedangkan penilaian dari tutor, skenario ini cukup baik menjadi pemicu pembelajaran (nilai rerata $>3,5$ ).

Tabel 1. Nilai rerata pernyataan 1 sampai 18 untuk skenario 3

\begin{tabular}{|c|c|c|c|}
\hline & \multirow{2}{*}{ Pernyataan } & \multicolumn{2}{|c|}{ Skenario 3} \\
\hline & & Tutor & Mahasiswa \\
\hline 1 & Skenario cukup terbuka untuk memperlancar diskusi & 4,10 & 3,38 \\
\hline 2 & Skenario mengarahkan diskusi yang optimal & 3,90 & 3,11 \\
\hline 3 & Skenario mengandung petunjuk sebagai pemicu diskusi & 3,80 & 2,92 \\
\hline 4 & Skenario memicu mahasiswa untuk merumuskan sasaran belajar bervariasi & 3,80 & 3,78 \\
\hline 5 & Skenario memicu mahasiswa mencari literatur yang relevan & 4,30 & 3,92 \\
\hline 6 & Skenario memicu mahasiswa ke arah diskusi yang efektif & 4,10 & 3,42 \\
\hline 7 & Skenario dirumuskan untuk mengarahkan ke satu atau lebih sasaran belajar modul & 4,00 & 3,81 \\
\hline 8 & Skenario mendorong integrasi dari berbagai disiplin ilmu & 4,10 & 3,73 \\
\hline 9 & $\begin{array}{l}\text { Skenario mendorong mahasiswa untuk menggunakan literatur yang berkaitan } \\
\text { dengan sasaran pembelajaran modul }\end{array}$ & 4,30 & 3,92 \\
\hline 10 & $\begin{array}{l}\text { Skenario diformulasikan sedemikian rupa sehingga meningkatkan ketertarikan } \\
\text { terhadap materi }\end{array}$ & 3,80 & 3,37 \\
\hline 11 & $\begin{array}{l}\text { Skenario disusun sesuai dengan wawasan mahasiswa tentang lingkungan dan } \\
\text { kebudayaan mereka }\end{array}$ & $\mathbf{3 , 5 0}$ & 3,28 \\
\hline 12 & Skenario tampak menarik bagi mahasiswa & 3,70 & 3,12 \\
\hline 13 & Skenario menunjukkan hubungan yang jelas dengan profesi di masa depan & 4,00 & 4,08 \\
\hline 14 & Konsep ilmu dasar disajikan dalam konteks masalah klinis & 4,00 & 3,76 \\
\hline 15 & Skenario berhubungan dengan pasien secara holistik dan tidak hanya penyakit saja & 3,89 & 3,59 \\
\hline 16 & Skenario disusun sesuai dengan level pengetahuan awal mahasiswa & 3,78 & 3,41 \\
\hline 17 & Skenario sejalan dengan materi kurikulum yang telah dipelajari sebelumnya & 4,11 & 3,66 \\
\hline 18 & $\begin{array}{l}\text { Mahasiswa telah mengenal sebagian pengetahuan yang diperlukan untuk } \\
\text { mendiskusikan skenario }\end{array}$ & 3,89 & 3,41 \\
\hline
\end{tabular}

Seorang laki-laki berusia 20 tahun datang ke Puskesmas Bahu Poliklinik dengan keluhan mata berwarna kuning sejak 1 minggu yang lalu. Kulit diseluruh tubuh juga terlihat kuning. Penderita juga mengeluh badan terasa lemah dan nafsu makan menurun.

Gambar 3. Skenario 3 
Skenario tiga ini dapat dikategorikan pada tipe skenario yang membutuhkan penjelasan (explanation problem). Secara umum, explanation problem terdiri dari deskripsi dari sejumlah fenomena yang saling terkait dan penjelasan terhadap terjadinya fenomena dan keterkaitannya perlu dicari. Misalnya, penjelasan terhadap terjadinya tanda dan gejala yang diidentifikasi dari skenario. Tujuan dari tipe masalah ini ialah mahasiswa dapat menjelaskan dan memahami struktur dan mekanisme dasar. ${ }^{4}$ Mahasiswa biasanya kurang menyukai tipe skenario ini karena tipe seperti ini menuntut mahasiswa untuk mencari dan menjelaskan semua gejala dan diagnosis yang mungkin. Untuk tipe skenario seperti ini mungkin dapat divariasikan formatnya misalnya dalam bentuk video atau gambar sehingga lebih menarik.

\section{SIMPULAN}

Berdasarkan hasil penelitian dapat disimpulkan bahwa secara umum skenario PBL mempunyai kualitas yang cukup baik bila dinilai dari keenam faktor yang memengaruhi kualitas suatu skenario PBL.

Pada level yang lebih spesifik, dari penilaian skenario yang mendapatkan nilai paling rendah didapatkan aspek yang harus diperbaiki antara lain: skenario harus dirancang sedemikian rupa agar memicu berpikir, analisis, dan bernalar.

\section{DAFTAR PUSTAKA}

1. Albanese MA. Problem-based learning. In: Swanwick T, editor. Understanding Medical Education: Evidence, theory and practice (1st ed). London: Wi lley Blackwell, 2010; p. 37-52.

2. Konsil Kedokteran Indonesia. Standar Pendidikan Profesi Dokter (2nd ed). Jakarta: KKI, 2012.

3. Munshi F, Zayat E, Dolmans D. Development and utility of a questionnaire to evaluate the quality of PBL problems. South East Asian Journal of Medical Education. 2008;2(2):32-40.

4. Schmidt HG. Problem-based learning: Rationale and description. Medical Education. 1983;17:11-6.

5. Dolmans DHJM, Snellen-Balendong $H$. Problem construction. Maastricht: Datawyse Maastricht University, 2000: p. 9-15.

6. Dolmans DHJM, Snellen-Balendong, H, Wolfhagen IHAP, Van der Vleuten CPM. Seven principles of effective case design for a problem based curriculum. Medical Teacher. 1997: 19(3):185-9.

7. Amin Z, Khoo HE. Basics in Medical Education (2nd ed). Singapore: World Scientific Publishing Co.Pte.Ltd, 2009. 